\title{
Prenatal nicotine exposure enhances Cx43 and Panx1 unopposed channel activity in brain cells of adult offspring mice fed a high-fat/cholesterol diet
}

\author{
Juan A. Orellana ${ }^{1 *}$, Dolores Busso ${ }^{2,3}$, Gigliola Ramírez ${ }^{1}$, Marlys Campos ${ }^{4}$, Attilio Rigotti2,3, \\ Jaime Eugenín ${ }^{4}$ and Rommy von Bernhardi ${ }^{1}$ \\ ${ }^{1}$ Departamento de Neurología, Escuela de Medicina, Pontificia Universidad Católica de Chile, Santiago, Chile \\ ${ }^{2}$ Departamento de Nutrición, Diabetes y Metabolismo, Escuela de Medicina, Pontificia Universidad Católica de Chile, Santiago, Chile \\ ${ }^{3}$ Centro de Nutrición Molecular y Enfermedades Crónicas, Escuela de Medicina, Pontificia Universidad Católica de Chile, Santiago, Chile \\ ${ }^{4}$ Laboratorio de Sistemas Neurales, Departamento de Biología, Facultad de Química y Biología, Universidad de Santiago de Chile, Santiago, Chile
}

Edited by:

Francesco Moccia, University of

Pavia, Italy

\section{Reviewed by:}

Bernhard H. Rauch, University

Medicine Greifswald, Germany

Brian David Gulbransen, Michigan

State University, USA

${ }^{*}$ Correspondence:

Juan A. Orellana, Departamento de Neurología, Escuela de Medicina,

Pontificia Universidad Católica de Chile, Marcoleta 391, Santiago,

8330024, Chile

e-mail:jaorella@uc.cl
Nicotine, the most important neuroteratogen of tobacco smoke, can reproduce brain and cognitive disturbances per se when administered prenatally. However, it is still unknown if paracrine signaling among brain cells participates in prenatal nicotine-induced brain impairment of adult offspring. Paracrine signaling is partly mediated by unopposed channels formed by connexins hemichannels ( $\mathrm{HCs}$ ) and pannexins serving as aqueous pores permeable to ions and small signaling molecules, allowing exchange between the intra- and extracellular milieus. Our aim was to address whether prenatal nicotine exposure changes the activity of those channels in adult mice offspring under control conditions or subjected to a second challenge during young ages: high-fat/cholesterol (HFC) diet. To induce prenatal exposure to nicotine, osmotic minipumps were implanted in CF1 pregnant mice at gestational day 5 to deliver nicotine bitartrate or saline (control) solutions. After weaning, offspring of nicotine-treated or untreated pregnant mice were fed ad libitum with chow or HFC diets for 8 weeks. The functional state of connexin 43 (Cx43) and pannexin 1 (Panx1) unopposed channels was evaluated by dye uptake experiments in hippocampal slices from 11-week-old mice. We found that prenatal nicotine increased the opening of $\mathrm{C} \times 43 \mathrm{HCs}$ in astrocytes, and Panx 1 channels in microglia and neurons only if offspring mice were fed with HFC diet. Blockade of inducible nitric oxide synthase (iNOS), cyclooxygenase $2\left(\mathrm{COX}_{2}\right)$ and prostaglandin $\mathrm{E}$ receptor $1\left(\mathrm{EP}_{1}\right)$, ionotropic ATP receptor type $7\left(\mathrm{P}_{2} \mathrm{X}_{7}\right)$ and NMDA receptors, showed differential inhibition of prenatal nicotine-induced channel opening in glial cells and neurons. Importantly, inhibition of the above mentioned enzymes and receptors, or blockade of $\mathrm{C} \times 43$ and Panx1 unopposed channels greatly reduced adenosine triphosphate (ATP) and glutamate release from hippocampal slices of prenatally nicotine-exposed offspring. We propose that unregulated gliotransmitter release through Cx43 and Panx1 unopposed channels may participate in brain alterations observed in offspring of mothers exposed to tobacco smoke during pregnancy.

Keywords: hemichannels, connexins, pannexins, nicotine, brain, glia, fat diet

\section{INTRODUCTION}

A growing body of evidence indicates that the risk of developing chronic diseases throughout life is related to environmental factors acting on tissue plasticity at specific windows during fetal development. Maternal cigarette smoking is a well established environmental risk factor associated with adverse effects on fetal outcome, increasing perinatal morbidity and mortality, and evoking long-term behavioral, learning, and memory impairment in the offspring (Naeye and Peters, 1984; Rantakallio and Koiranen, 1987; DiFranza and Lew, 1995; Jacobsen et al., 2006; Julvez et al., 2007). Nicotine is the most important neuroteratogen component of tobacco smoke and, given that it easily crosses the placental and blood-brain barriers (Luck et al., 1985), it is believed to have a dramatic influence on healthy brain development via activation of fetal nicotinic receptors (Dwyer et al., 2008). Indeed, nicotine delivery during pregnancy, eliciting plasma levels comparable to those found in heavy smokers, induces activation of apoptosis-associated genes, long-lasting morphological alterations of neurons, reduced neuronal cell layer thickness, increased number of glial cells, and behavioral impairment (Navarro et al., 1989; Roy and Sabherwal, 1998; Roy et al., 2002; Eugenín et al., 2008). Several studies have attempted to understand the mechanism underlying these nicotine-induced consequences by examining alterations in neurotransmitters (Navarro et al., 1989; Muneoka et al., 1997), changes in nicotinic receptor availability (van de Kamp and Collins, 1994; Coddou et al., 2009), 
modifications in gene expression (Toledo-Rodriguez et al., 2010; Schneider et al., 2011), and early adaptations of dendritic morphology (Roy and Sabherwal, 1994, 1998). However, the impact of maternal nicotine exposure on the communication of neurons with their partnership cells, the glia, has received little attention.

It is nowadays well established that glial cells express virtually all known neurotransmitter receptors types, allowing them to sense neuronal activity and microenvironmental changes by responding locally through the $\mathrm{Ca}^{2+}$-dependent release of bioactive molecules termed "gliotransmitters" (e.g., glutamate, adenosine triphosphate (ATP), adenosine, GABA, and D-serine; Perea et al., 2009; Perea and Araque, 2010). In the central nervous system (CNS), gliotransmitter release is in part mediated by the opening of unopposed membrane channels formed by connexins hemichannels (HCs) or pannexins (Wang et al., 2013b). These channels serve as aqueous pores permeable to ions and small molecules, allowing for diffusional exchange between the intraand extracellular compartments. In glial cells, HCs and pannexin channels (PCHs) grant the release of gliotransmitters that are necessary for different brain functions including glucosensing (Orellana et al., 2012), ischemic tolerance (Lin et al., 2008), fear memory consolidation (Stehberg et al., 2012), neuron-glia crosstalk (Torres et al., 2012), and chemoreception (Huckstepp et al., 2010). However, several independent studies have pointed out that onset and progression of neurodegenerative homeostatic imbalances may be associated to impairment in permeability properties of these channels in the CNS (Takeuchi et al., 2006; Thompson et al., 2006; Karpuk et al., 2011; Orellana et al., 2011a,b; Gulbransen et al., 2012; Burkovetskaya et al., 2014). Therefore, we decided to investigate whether prenatal nicotine exposure could affect the functional activity of HCs and PCHs in glial cells and neurons in the offspring. Different maternal conditions during pregnancy, including prenatal nicotine, have been shown to sensitize the brain of the adult offspring on its response to a subsequent environmental challenge (Slotkin et al., 1991; Bilbo et al., 2005). Given that fat and cholesterol-enriched diets impair synaptic transmission and glial cell function (Dufour et al., 2006; Triviño et al., 2006; Ya et al., 2013), we studied if dyslipidemia induced by feeding a high-fat/cholesterol (HFC) diet in combination with prenatal nicotine exposure could enhance the opening of connexin and pannexin unopposed channels in the offspring brain. We chose dyslipidemia as a second environmental hit due to the high prevalence of this metabolic condition as a consequence of sedentary lifestyle and overnutrition in Western populations in the last decades.

In this work, we show that prenatal nicotine can increase the opening of unopposed channels formed by connexin 43 (Cx43) in astrocytes and pannexin 1 (Panx1) in microglia and neurons. Interestingly, these responses were only detected when offspring mice were subjected to dyslipidemia induced by feeding them a HFC diet.

\section{MATERIALS AND METHODS REAGENTS AND ANTIBODIES}

Gap26, Gap19; YGRKKRRQRRRDGANVDMHLKQIEIKKFKY GIEEHGK (TAT-L2) and ${ }^{10}$ panx1 peptides were obtained from
Genscript (New Jersey, USA). HEPES, DMEM, DNAse I, poly-L-lysine, LN-6, ns-398, sc-19220, polyclonal anti-Cx43 antibody, 3-(2-carboxypiperazin-4-yl)propyl-1-phosphonic acid (CPP), Brilliant blue G (BBG), oATP, ethidium (Etd) bromide, and probenecid (Prob) were purchased from Sigma-Aldrich (St. Louis, MO, USA). Fetal calf serum (FCS) was obtained from Hyclone (Logan, UT, USA). Penicillin, streptomycin, polyclonal anti-Panx1 antibody (PI488000), goat anti-mouse Alexa Fluor 488 and goat anti-mouse Alexa Fluor 555 were obtained from Invitrogen (Carlsbad, CA, USA). Anti-NeuN monoclonal antibody was obtained from Chemicon (Martinsried/Munich, Germany). Normal goat serum (NGS) was purchased from Zymed (San Francisco, CA, USA). Anti-GFAP monoclonal antibody was purchased from ICN Chemicals, (Irvine, CA). AntiCx43 monoclonal antibody was obtained from BD Biosciences (Franklin Lakes, NJ, USA).

\section{ANIMAL CARE AND USE}

All animal experimentation was conducted in accordance with the guidelines for care and use of experimental animals of the National Institute of Health (NIH) and local guidance documents generated by the ad hoc committee of the Chilean National Commission of Scientific and Technological Research (CONICYT). The procedures and research plan were approved by the Universidad de Santiago Bioethics Committee. CF-1 mice were obtained from the Public Health Institute and housed at the animal facility of the Laboratory of Neural Systems, Universidad de Santiago de Chile. Mice were housed under a 12-h lightdarkness condition, with access to ad libitum fresh water and food in a temperature $\left(18-26^{\circ} \mathrm{C}\right)$ - and humidity (40-70\%)-controlled and well ventilated environment.

\section{PRENATAL NICOTINE EXPOSURE AND POSTNATAL FEEDING WITH HFC DIET}

Subcutaneous implantation of osmotic minipumps (model 2004, Alzet) was performed in CF1 pregnant mice at gestational day 5 as previously described (Eugenín et al., 2008). In brief, pumps were implanted through an incision made between scapulae, using strict aseptic conditions, under anesthesia with $60-80 / 20 \mathrm{mg} / \mathrm{kg}$ ketamine/xylazine by intraperitoneal (i.p.) injection. Pumps delivered saline (controls) or nicotine bitartrate $\left(60 \mathrm{mg} \mathrm{kg}^{-1}\right.$ day $^{-1}$ ) at a rate of $0.25 \mu \mathrm{h}^{-1}$. Recovery from anesthesia was performed under controlled temperature. Dams were maintained in separate cages and daily supervision was done based on the protocol by Morton and Griffiths (Morton and Griffiths, 1985). After weaning, offspring of nicotine-treated or vehicle-treated pregnant mice were fed ad libitum with chow or HFC diet $(1.25 \%$ cholesterol, $15 \%$ total fat, and $0.5 \%$ cholic acid; Harlan Teklad, USA) for 8 weeks. This dietary condition induced a $\sim 2-3$ fold increase in total plasma cholesterol with no significant effect in body weight (not shown).

\section{ACUTE HIPPOCAMPAL SLICES}

Eleven-week-old offspring mice were decapitated, and their brains were dissected and placed in ice-cold artificial cerebrospinal fluid (ACSF) containing (in $\mathrm{mM}$ ): $125 \mathrm{NaCl}, 2.5 \mathrm{KCl}$, 25 glucose, $25 \mathrm{NaHCO}_{3}, 1.25 \mathrm{NaH}_{2} \mathrm{PO}_{4}, 2 \mathrm{CaCl}_{2}$, and $1 \mathrm{MgCl}_{2}$, 
bubbled with $95 \% \mathrm{O}_{2} / 5 \% \mathrm{CO}_{2}, \mathrm{pH}$ 7.4. Hippocampal coronal brain slices $(400 \mu \mathrm{m})$ were cut using a vibratome (Leica, VT 1000GS; Leica, Wetzlar, Germany) filled with ice-cold ACSF. The slices were transferred at room temperature $\left(20-22^{\circ} \mathrm{C}\right)$ to a holding chamber and immersed in oxygenated ACSF, $\mathrm{pH} 7.4$, for a stabilization period of $30 \mathrm{~min}$ before being used.

\section{DYE UPTAKE AND CONFOCAL MICROSCOPY}

For "snapshot" experiments, acute slices were incubated with $100 \mu \mathrm{M}$ Etd for $15 \mathrm{~min}$ in a chamber with oxygenated $\left(95 \% \mathrm{O}_{2}\right.$ and $5 \% \mathrm{CO}_{2}$ ) ACSF, $\mathrm{pH} 7.4$. Then, they were washed five times with ACSF, fixed at room temperature with $4 \%$ paraformaldehyde for $30 \mathrm{~min}$, rinsed extensively in phosphate buffered saline (PBS) and stored overnight at $4^{\circ} \mathrm{C}$ with cryoprotectant $(30 \%$ sucrose). Next day, slices were frozen and cut into 12-16 $\mu \mathrm{m}$ thick cryosections with a cryostat. Cryosections were incubated in $0.1 \%$ PBS-Triton X-100 containing 10\% NGS for $30 \mathrm{~min}$. Afterwards, they were incubated overnight at $4^{\circ} \mathrm{C}$ with antiIba-1 polyclonal antibody (1:300, Wako), anti-GFAP monoclonal antibody (1:300, Sigma), anti-NeuN monoclonal antibody (1:400, Chemicon), polyclonal anti-Cx43 (1:600, Sigma) or polyclonal anti-Panx1 (1:600, Invitrogen) diluted in 0.1\% PBS-Triton X-100 with $2 \%$ NGS. After five rinses in $0.1 \%$ PBS-Triton X-100, cryosections were incubated with goat anti-rabbit Alexa Fluor 488 (1:1500), goat anti-mouse Alexa Fluor 488 (1:1500) or goat anti-mouse Alexa Fluor 647 (1:1500) at room temperature for 1 h. After several washes, coverslips were mounted in Fluoromount and examined in a confocal laser-scanning microscope (Olympus Fluoview FV1000, Tokyo, Japan). Stacks of consecutive confocal images taken with a $63 \mathrm{X}$ objective at $500 \mathrm{~nm}$ intervals were sequentially acquired with two lasers (argon $488 \mathrm{~nm}$ and helium/neon $543 \mathrm{~nm}$ ), and $\mathrm{Z}$ projections were reconstructed using Fluoview software. The dye uptake ratio was calculated as the subtraction (F-F0) between the fluorescence (F) from respective cell and the background fluorescence (F0). At least six cells by field were selected from at least three fields in each hippocampal slice. Gap26, Gap19; TAT-L2, ${ }^{10}$ panx1, probenecid, L-N6, ns-398, sc-19220, CPP, BBG and oATP were pre-incubated 15 min and then coapplied with Etd for "snapshot" experiments.

\section{MEASUREMENT OF EXTRACELLULAR ATP AND GLUTAMATE CONCENTRATION}

Acute hippocampal slices were immersed in oxygenated ACSF, $\mathrm{pH}$ 7.4 , at room temperature $\left(20-22^{\circ} \mathrm{C}\right)$ for $30 \mathrm{~min}$. Then, ATP and glutamate concentration in the extracellular solution were measured using a luciferin/luciferase bioluminescence and glutamate assay kit (Sigma-Aldrich), respectively. The amount of ATP and glutamate in each sample were calculated from standard curves and normalized by the protein concentration. Briefly, after the experiments, slices were washed twice with ACSF solution and sonicated in ice-cold PBS containing $5 \mu \mathrm{M}$ ethylenediaminetetraacetic acid (EDTA), Halt (78440) and T-PER protein extraction cocktail (78510), according to manufacturer instructions (Pierce, Rockford, IL). Proteins were measured using the Bio-Rad protein assay. Gap 26, Gap 19; TAT-L2, ${ }^{10}$ panx1, probenecid, LN-6, ns398, sc-19220, CPP, BBG and oATP were pre-incubated $30 \mathrm{~min}$ before the measurements.

\section{IL-1 $\beta$ AND TNF- $\alpha$ ASSAY}

IL- $1 \beta$ and TNF- $\alpha$ were determined in $100 \mu \mathrm{L}$ of sera. Samples were centrifuged at $14,000 \mathrm{~g}$ for $40 \mathrm{~min}$. Supernatants were collected and protein content assayed by the BCA method. IL- $1 \beta$ and TNF- $\alpha$ levels were determined by sandwich ELISA, according to the manufacturer's protocol (eBioscience, San Diego, CA, USA). For the assay, $100 \mu \mathrm{l}$ of samples were added per ELISA plate well and incubated at $4^{\circ} \mathrm{C}$ overnight. A calibration curve with recombinant cytokine was included. Detection antibody was incubated at room temperature for $1 \mathrm{~h}$ and the reaction developed with avidin-HRP and substrate solution. Absorbance was measured at $450 \mathrm{~nm}$ with reference to $570 \mathrm{~nm}$ with the microplate reader Synergy HT (Biotek Instruments).

\section{DATA ANALYSIS AND STATISTICS}

For each data group, results were expressed as mean \pm standard error (SEM); $\mathrm{n}$ refers to the number of independent experiments. For statistical analysis, each treatment was compared with its corresponding control, and significance was determined using a one-way ANOVA followed, in case of significance, by a Tukey post hoc test.

\section{RESULTS}

\section{PRENATAL NICOTINE ENHANCES CX43 AND PANX1 UNOPPOSED CHANNEL ACTIVITY IN BRAIN CELLS OF OFFSPRING MICE FED A HIGH-FAT/CHOLESTEROL DIET}

Nicotine delivery during pregnancy induces neuronal alterations and behavioral impairment (Navarro et al., 1989; Roy and Sabherwal, 1998; Roy et al., 2002). On the other hand, the opening of HCs and PCHs has been linked to glial cell dysfunction and neuronal impairment (Takeuchi et al., 2006; Orellana et al., 2011a,b, 2013; Shestopalov and Slepak, 2014). Therefore, we investigated whether prenatal nicotine exposure could affect the functional activity of these channels in microglia, astrocytes and neurons of the offspring. To address this, we examined $\mathrm{HC}$ and $\mathrm{PCH}$ activity by measuring Etd uptake in acute hippocampal slices from 11-week-old offspring. Etd is a molecule that crosses the plasma membrane in healthy cells by passing through specific large channels, including connexin and pannexin unopposed channels. Upon binding to intracellular nucleic acids, Etd becomes fluorescent, indicating channel opening when appropriate blockers are employed (Schalper et al., 2008; Sáez and Leybaert, 2014). Etd uptake by Iba-1-positive microglia, GFAP-positive astrocytes and NeuN-positive neurons on acute hippocampal slices was evaluated in "snapshot" experiments. Microglia, astrocytes and neurons from offspring of control dams showed a low Etd uptake ratio (Figures $\mathbf{1 A}-\mathbf{H}, \mathbf{2 A}-\mathbf{H}, \mathbf{3 A}-\mathbf{H}$ ) as previously reported (Orellana et al., 2010; Karpuk et al., 2011). Interestingly, prenatal exposure to nicotine did not change Etd uptake in brain cells in the offspring compared to control conditions (Figures 1Q, 2Q, 3Q).

Further, we evaluated whether prenatal nicotine sensitized the brain of adult offspring on its response to a HFC diet. Similarly to what was observed in the offspring from control dams fed a chow diet, Etd uptake remained low when the offspring from control dams was fed a HFC diet (Figures 1Q, 2Q, 3Q). However, HFC diet increased Etd uptake in microglia, astrocytes and pyramidal 


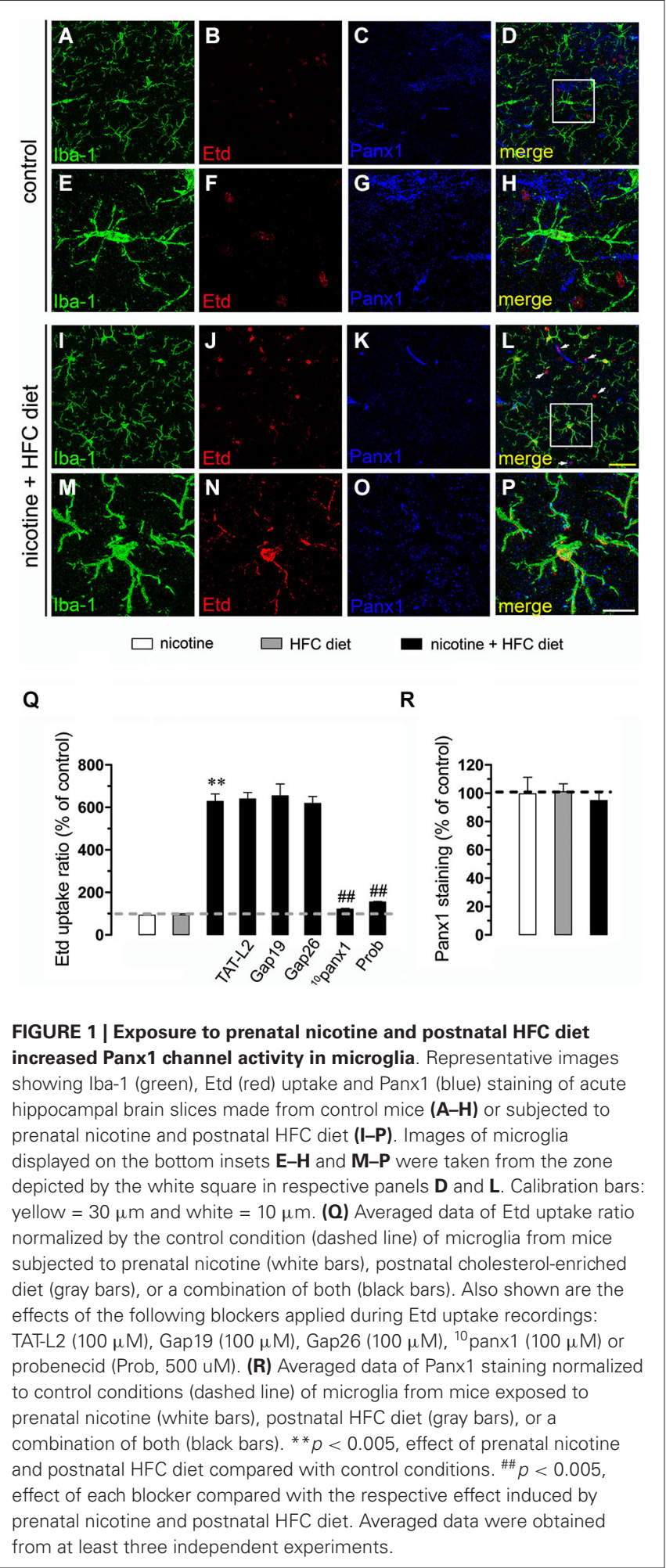

neurons when the offspring came from nicotine-treated dams (Figures 1I-Q, 2I-Q, 3I-Q). Microglia express functional unopposed channels formed by Panx1 and Cx43 (Orellana et al., 2011b). The possible role of Panxl channels in nicotine-evoked Etd uptake was studied using probenecid and the mimetic peptide

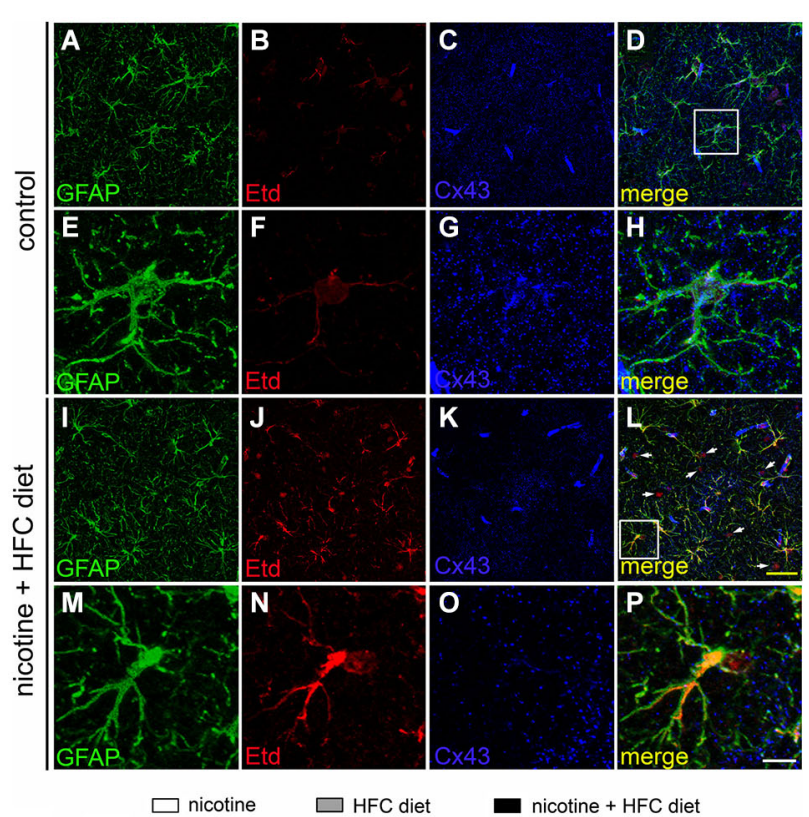

Q

$\mathbf{R}$

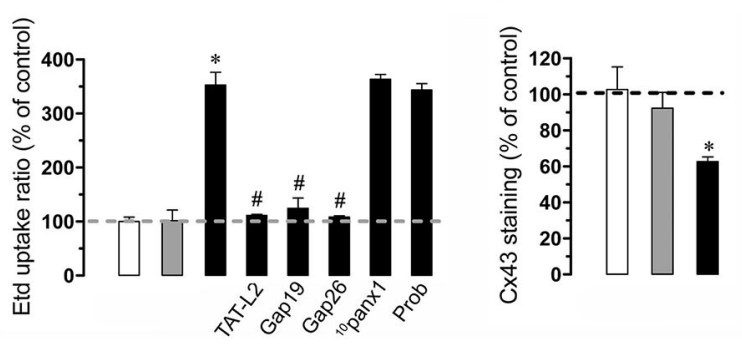

FIGURE 2 | Exposure to prenatal nicotine and postnatal HFC diet increased Cx43 HC activity in astrocytes. Representative images showing GFAP (green), Etd (red) uptake and Cx43 (blue) staining of acute hippocampal brain slices made from control mice $\mathbf{( A - H )}$ or subjected to prenatal nicotine and postnatal HFC diet (I-P). Images of hippocampal astrocytes displayed on the bottom insets $\mathbf{E}-\mathbf{H}$ and $\mathbf{M}-\mathbf{P}$ were taken from the zone depicted by the white square in respective panels $\mathbf{D}$ and $\mathbf{L}$. Calibration bars: yellow $=70 \mu \mathrm{m}$ and white $=20 \mu \mathrm{m}(\mathbf{0})$ Averaged data of Etd uptake ratio normalized to control conditions (dashed line) of astrocytes from mice exposed to prenatal nicotine (white bars), postnatal HFC diet (gray bars), or a combination of both (black bars). Also shown are the effects of the following blockers applied during Etd uptake recordings: TAT-L2 (100 $\mu \mathrm{M})$, Gap19 $(100 \mu \mathrm{M})$, Gap26 $(100 \mu \mathrm{M}),{ }^{10} \mathrm{pan} \times 1(100 \mu \mathrm{M})$ or probenecid (Prob, 500 uM). (R) Averaged data of Cx43 staining normalized to control conditions (dashed line) of astrocytes from mice exposed to prenatal nicotine (white bars), postnatal HFC diet (gray bars), or a combination of both (black bars). ${ }^{*} p<0.05$, effect of prenatal nicotine and postnatal HFC diet compared with control conditions. ${ }^{\#} p<0.05$, effect of each blocker compared with the effect induced by prenatal nicotine plus a postnatal HFC diet. Averaged data were obtained from at least three independent experiments.

${ }^{10}$ panx 1 with an amino acid sequence homologous to the second loop of Panx1 (Pelegrin and Surprenant, 2006; Silverman et al., 2008). Probenecid $(500 \mu \mathrm{M})$ and ${ }^{10}$ panxl $(200 \mu \mathrm{M})$ nearly abolished the increased microglial cell Etd uptake triggered by prenatal nicotine and postnatal HFC diet (Figures 1I-Q). In contrast, 
mimetic peptides homologous to the cytoplasmic (TAT-L2 and Gap19; $100 \mu \mathrm{M})$ or first extracellular (Gap26; $100 \mu \mathrm{M})$ loop of Cx43 (Wang et al., 2013a), did not reduce nicotine-induced Etd uptake by microglia (Figure 1Q).

Astrocytes express functional unopposed channels formed by Cx43 (Contreras et al., 2002) and Panx1 (Iglesias et al., 2009). Thereby, we used TAT-L2, Gap19, Gap26, probenecid and ${ }^{10}$ panx1 to determine the contribution of both channels in the nicotineinduced Etd uptake by astrocytes. TAT-L2 (100 $\mu \mathrm{M})$, Gap19 $(100 \mu \mathrm{M})$ and Gap26 $(100 \mu \mathrm{M})$ fully reduced astroglial cell Etd uptake evoked by prenatal nicotine and postnatal HFC diet (Figure 2Q). In contrast, ${ }^{10}$ panx1 $(100 \mu \mathrm{M})$ and probenecid $(500 \mu \mathrm{M})$ failed to induce the same inhibition (Figure 2Q).

For neurons, most evidence support that they express unopposed channels formed by Panxl (Thompson et al., 2006). In agreement with that evidence, ${ }^{10}$ panx 1 and probenecid strongly reduced the nicotine and postnatal HFC diet-induced Etd uptake observed in pyramidal neurons (Figure 3Q), whereas TAT-L2, Gap19 and Gap26 failed to cause a similar response (Figure 3Q). Overall, these data support the idea that prenatal nicotine plus postnatal HFC diet increases the opening of unopposed channels formed by $\mathrm{Cx} 43$ in astrocytes and Panx1 in microglia and neurons.

\section{PRENATAL NICOTINE AFFECTS LEVELS OF CX43 AND PANX1 IN BRAIN CELLS OF OFFSPRING MICE FED A HIGH-FAT/CHOLESTEROL DIET}

Given that pathological conditions affect the expression of connexins and pannexins in the CNS (Rouach et al., 2002; Orellana et al., 2009), we examined whether prenatal nicotine plus postnatal HFC diet could modulate $\mathrm{Cx} 43$ and Panx1 levels in brain cells by confocal analysis. As expected, neither prenatal nicotine nor postnatal HFC diet alone affected Cx43 and Panx1 levels in astrocytes and neurons, respectively (Figures 2R, 3R). However, combination of prenatal nicotine plus feeding a HFC diet during adulthood reduced Cx43 levels in astrocytes (Figure 2R), whereas in pyramidal neurons, immunodetection of Panx1 was increased (Figure 3R). For all tested conditions, Panx1 remained unchanged in microglia (Figure 1R).

\section{INCREASED OPENING OF CX43 AND PANX1 UNOPPOSED CHANNELS IN NICOTINE AND HIGH-FAT/CHOLESTEROL EXPOSED OFFSPRING BRAIN DEPENDS ON INOS/COX2/EP1 RECEPTOR PATHWAY AND PURINERGIC/GLUTAMATERGIC SIGNALING}

Under neuroinflammatory conditions, glial cells exhibit a prominent activation of inducible nitric oxide (NO) synthase (iNOS) and cyclooxygenase $2\left(\mathrm{COX}_{2}\right.$; Tzeng et al., 2005; Amitai, 2010), two enzymes that produce mediators ( $\mathrm{NO}$ and prostaglandins, respectively) linked to the opening of $\mathrm{Cx} 43$ and Panxl unopposed channels (Retamal et al., 2007; Orellana et al., 2013). Accordingly, we investigated the contribution of iNOS and $\mathrm{COX}_{2}$ activation on Etd uptake induced by prenatal nicotine and postnatal HFC diet. Notably, iNOS and $\mathrm{COX}_{2}$ inhibition by L-N6 $(1 \mu \mathrm{M})$ and ns-398 (5 $\mu \mathrm{M})$, respectively, greatly reduced Etd uptake induced by prenatal nicotine and postnatal HFC diet in microglia, astrocytes and pyramidal neurons (Figure 4). It has been previously shown that iNOS-dependent release of NO increases $\mathrm{COX}_{2}$ activity and prostaglandin $\mathrm{E}_{2}\left(\mathrm{PEG}_{2}\right)$ production

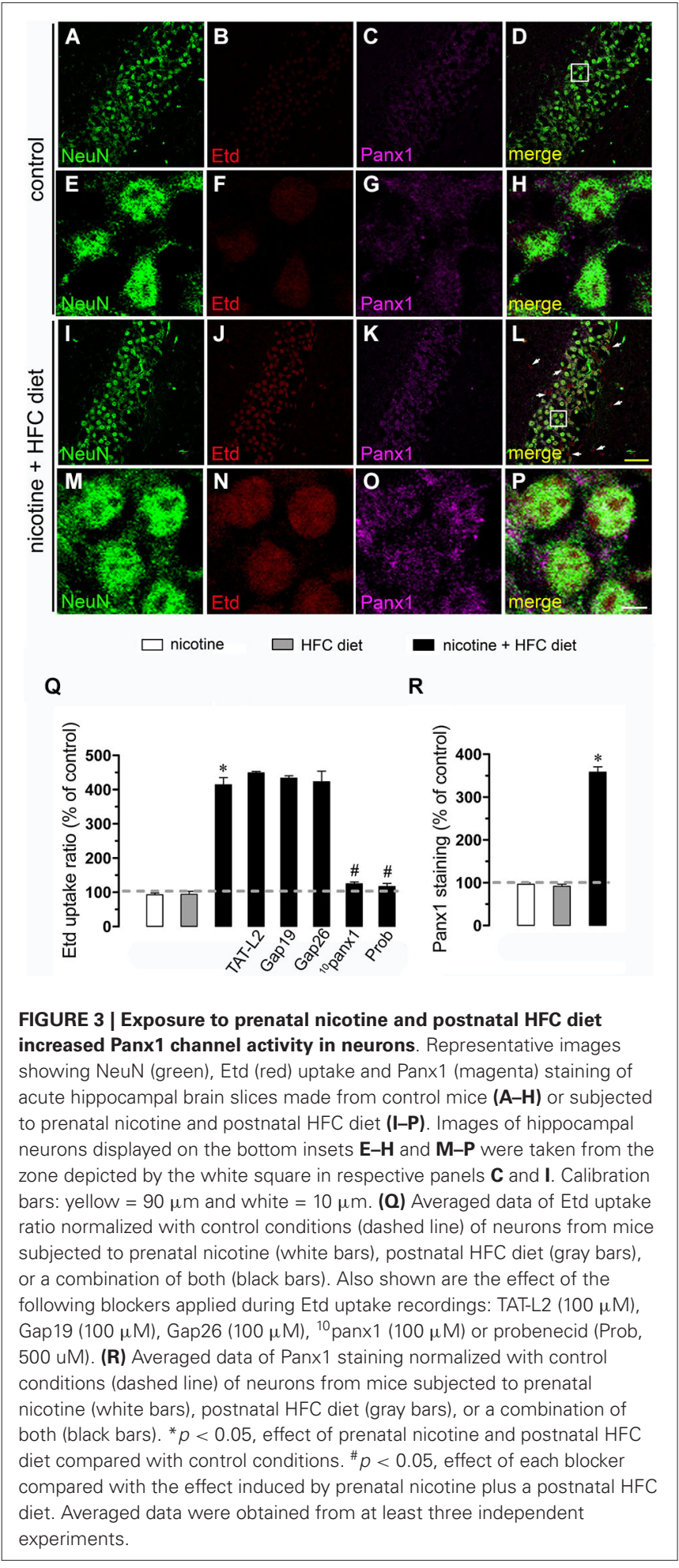

in macrophages (Salvemini et al., 1993). Importantly, $\mathrm{PEG}_{2}$ activates $\mathrm{G}$ protein-coupled receptor $1\left(\mathrm{EP}_{1}\right)$, increasing the intracellular free $\mathrm{Ca}^{2+}$ concentration $\left(\left[\mathrm{Ca}^{2+}\right]_{i}\right.$; Woodward et al., 2011), causing opening of Panx1 unopposed channels (Orellana et al., 2013). Thus, we assessed whether the $\mathrm{EP}_{1}$ receptor participated in the above mentioned responses. Inhibition of the $\mathrm{EP}_{1}$ receptor 


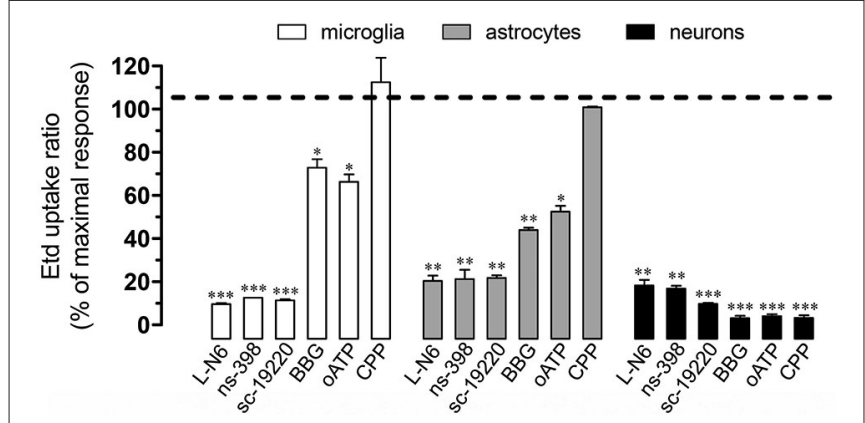

FIGURE 4 | Cx43 and Panx1 unopposed channel activity evoked by prenatal nicotine and postnatal HFC diet depended on the iNOS/COX $2 / \mathrm{EP}_{1}$ receptor pathway and NMDA/P2X 7 receptor signaling. Averaged data normalized to maximal Etd uptake ratio (dashed line) achieved by prenatal nicotine and postnatal HFC diet in microglia (white bars), astrocytes (gray bars) and neurons (black bars) treated with the following blockers during Etd uptake recordings: L-N6 (1 $\mu \mathrm{M})$, ns-398 (5 $\mu \mathrm{M}), \mathrm{sc}-19220(20 \mu \mathrm{M}), \mathrm{BBG}(200 \mu \mathrm{M})$, oATP $(10 \mu \mathrm{M})$ and CPP $(20 \mu \mathrm{M})$. ${ }^{*} p<0.05$, ${ }^{*} p<0.005 ;{ }^{* *} p<0.001$, effect of each blocker compared with the effect induced by prenatal nicotine plus a postnatal HFC diet. Averaged data were obtained from at least three independent experiments.

with sc-19220 $(20 \mu \mathrm{M})$ resulted in a prominent reduction of the Etd uptake triggered by prenatal nicotine and postnatal HFC diet in microglia, astrocytes and pyramidal neurons (Figure 4).

When activated, glial cells release relevant amounts of gliotransmitters including ATP and glutamate, which underlie glia-to-glia communication via activation of purinergic and glutamatergic receptors (Perea et al., 2009; Perea and Araque, 2010). Because opening of HCs and PCHs has been asociated with purinergic and glutamatergic signaling (Locovei et al., 2006; Thompson et al., 2008; Orellana et al., 2011a,b), we examined if NDMA and ionotropic ATP receptor type $7\left(\mathrm{P}_{2} \mathrm{X}_{7}\right)$ receptors were involved in the Etd uptake induced by prenatal nicotine and postnatal HFC diet. Remarkably, BBG $(10 \mu \mathrm{M})$ and oATP $(200 \mu \mathrm{M})$, two blockers of $\mathrm{P}_{2} \mathrm{X}_{7}$ receptors, partially reduced the nicotine-induced Etd uptake in microglia and astrocytes, whereas it achieved an almost complete inhibition on pyramidal neurons (Figure 4). In addition, the NMDA receptor blocker CPP $(20 \mu \mathrm{M})$, completely abolished Etd uptake evoked by prenatal nicotine and postnatal HFC diet in pyramidal neurons, whereas it failed to show the same inhibitory effect in glial cells (Figure 4). Taken together, these data indicate that the increase in Etd uptake induced by prenatal nicotine and postnatal HFC diet depended on activation of the $\mathrm{iNOS} / \mathrm{COX}_{2} / \mathrm{EP}_{1}$ receptor pathway and signaling via $\mathrm{P} 2 \mathrm{X}_{7} / \mathrm{NMDA}$ receptors.

\section{PRENATAL NICOTINE INDUCES CX43 AND PANX1-DEPENDENT RELEASE OF ATP AND GLUTAMATE IN BRAIN CELLS OF OFFSPRING MICE FED A HIGH-FAT/CHOLESTEROL DIET}

Recently, it has been demonstrated that gliotransmitters elicit their own release in an autocrine manner via Cx43 and Panx1 unopposed channels (Orellana et al., 2012, 2013). Given that NMDA/P $2 X_{7}$ receptors were involved in the Etd uptake observed
A

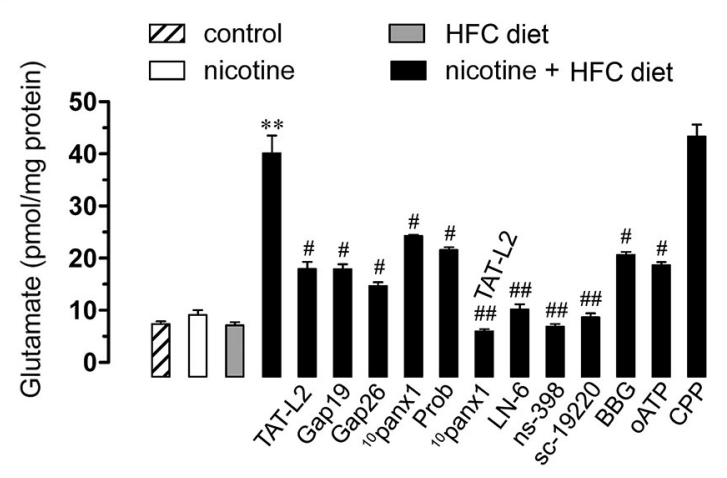

B

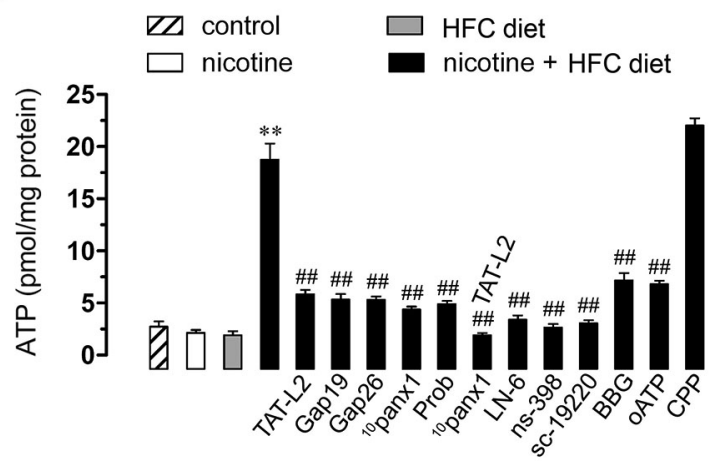

FIGURE 5 | Opening of $\mathrm{Cx} 43$ and Panx 1 unopposed channels allowed for the release of glutamate and ATP via the iNOS/COX $/ \mathrm{EP}_{1}$ receptor pathway and NMDA/P2X $X_{7}$ receptor signaling. Averaged data of glutamate (A) or ATP (B) release by hippocampal slices made from mice maintained under control conditions (dashed bar), or exposed to prenatal nicotine (white bar), postnatal HFC diet (gray bars) or a combination of both (black bars). Also shown are the effect of the following blockers applied during the experiments: TAT-L2 (100 $\mu$ M), Gap19 (100 $\mu \mathrm{M})$, Gap26 $(100 \mu \mathrm{M}),{ }^{10}$ panx1 $(100 \mu \mathrm{M})$, probenecid (Prob, $\left.500 \mathrm{uM}\right)$, L-N6, ns-398, sc-19220, BBG, oATP or CPP. ** $p<0.005$, effect of prenatal nicotine plus postnatal HFC diet compared with control conditions. ${ }^{\#} p<0.05$,

\#\# $p<0.005$; effect of each blocker compared with the effect induced by prenatal nicotine plus a postnatal HFC diet. Averaged data were obtained from at least three independent experiments.

in the offspring exposed to prenatal nicotine and fed a HFC diet during adulthood, we next evaluated whether glutamate and ATP release from hippocampal slices via Cx43 and/or Panx1 unopposed channels were also affected in this condition. Similarly to that observed in Etd uptake experiments, neither prenatal nicotine nor postnatal HFC diet by themselves affected the release of both gliotransmitters compared with control conditions (Figures 5A,B). However, the exposure to nicotine prenatally combined with a HFC diet during adult life strongly increased the release of glutamate and ATP (Figures 5A,B). Interestingly, TAT-L2 $(100 \mu \mathrm{M}), \operatorname{Gap} 19(100 \mu \mathrm{M})$ and Gap26 $(100 \mu \mathrm{M})$ prominently reduced the release of glutamate and ATP induced by prenatal nicotine and postnatal HFC diet (Figures 5A,B). Similar effects were observed on the release of glutamate and ATP upon treatment with ${ }^{10}$ panxl and probenecid (Figures 5A,B). Taken together, these results indicate that exposure to prenatal nicotine plus postnatal HFC diet increased the release of glutamate and 


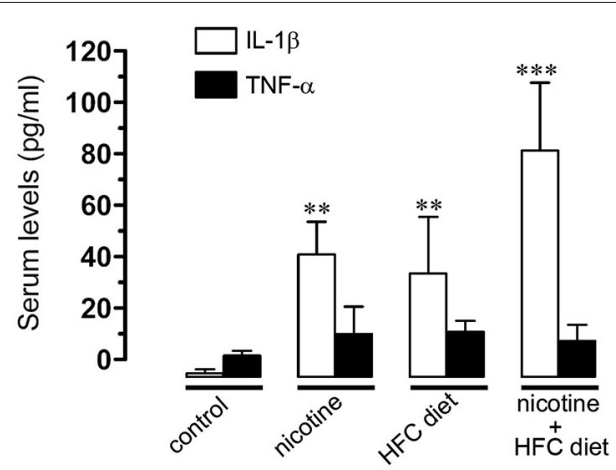

FIGURE 6 | Prenatal nicotine and postnatal HFC diet increased serum levels of IL-1 $\beta$. Averaged data of serum levels of IL-1 $\beta$ (white bars) and TNF- $\alpha$ (black bars) from mice under control conditions, or subjected to prenatal nicotine, postnatal HFC diet, or a combination of both conditions. ${ }^{* *} p<0.005,{ }^{* * *} p<0.001$; effect of treatments compared with control conditions. Averaged data were obtained from at least five animals.

ATP by the opening of unopposed channels formed by $\mathrm{Cx} 43$ and Panxl.

As expected, L-N6 (1 $\mu \mathrm{M})$, ns-398 $(5 \mu \mathrm{M})$ and sc-19220 $(20 \mu \mathrm{M})$ fully inhibited the release of glutamate and ATP triggered by prenatal nicotine exposure and HFC diet (Figures 5A,B). Furthermore, supporting the idea that gliotransmitters can elicit their own release, we found that BBG $(10 \mu \mathrm{M})$ and oATP $(200 \mu \mathrm{M})$ almost completely abolished the release of glutamate and ATP induced by prenatal nicotine and postnatal HFC diet. However, blockade of NMDA receptors with CPP did not show the same effect (Figures 5A,B). The evidence suggest that ATP but not glutamate, could partially evoke its own release by an autocrine pathway possibly mediated by $\mathrm{Cx} 43$ and Panx1 unopposed channels.

\section{PRENATAL NICOTINE AND POSTNATAL HIGH-FAT/CHOLESTEROL DIET INCREASED SERUM LEVELS OF IL-1 $\beta$}

Given that previous studies have shown that IL- $1 \beta$ and TNF- $\alpha$ increase the opening of $\mathrm{HCs}$ and PCHs in glial cells (Retamal et al., 2007; Froger et al., 2009, 2010; Sáez et al., 2013), we evaluated serum levels of IL- $1 \beta$ and TNF- $\alpha$ in the offspring. TNF- $\alpha$ levels remained unchanged at the various conditions. However, IL-1 $\beta$ was notably increased by prenatal nicotine or postnatal HFC diet alone, and by the combination of prenatal nicotine plus postnatal HFC diet, being the latest the condition achieving the most robust increase (Figure 6). This evidence indicates that opening of $\mathrm{Cx} 43$ and Panx1 unopposed channels evoked by prenatal nicotine exposure and postnatal HFC diet occurred concomitantly with an increased pro-inflammatory state of the offspring.

\section{DISCUSSION}

In this study, we showed that prenatal nicotine and postnatal HFC diet for 8 weeks after weaning increased the opening of unopposed channels formed by $\mathrm{Cx} 43$ in astrocytes and Panx1 in microglia and neurons. This enhanced opening occurred by a mechanism depending on $\mathrm{iNOS} / \mathrm{COX}_{2} / \mathrm{EP}_{1}$ receptor pathway activation and signaling via $\mathrm{P} 2 \mathrm{X}_{7} / \mathrm{NMDA}$ receptors. In addition, unopposed channel opening resulted in the release of two major gliotransmitters: glutamate and ATP.

Previous studies have demonstrated that nicotine delivery during pregnancy induces neuronal defects, increased number of glial cells, and behavioral impairment in the offspring (Navarro et al., 1989; Roy and Sabherwal, 1998; Roy et al., 2002). Our results suggest that the effect induced by prenatal nicotine could be mediated in part by enhanced release of gliotransmitters. It has been shown that gliotransmitter release through HCs and PCHs underlies crucial functions in the physiology of the CNS (Lin et al., 2008; Huckstepp et al., 2010; Orellana et al., 2012; Stehberg et al., 2012; Torres et al., 2012). Moreover, several studies indicate that uncontrolled opening of these channels results in exacerbated release of gliotransmitters, which in high concentrations can be toxic for neighboring cells (Takeuchi et al., 2006; Orellana et al., 2011a,b). Here, we found that prenatal nicotine in combination with a postnatal HFC diet increased the opening of HCs and PHCs in brain cells. In agreement with their sensor role in the CNS (Block et al., 2007), microglia showed the highest Etd uptake compared with astrocytes and neurons in mice exposed to both environmental stressors. As this response was nearly abolished by Panx1 but not Cx43 unopposed channel blockers, the former protein appeared to be the major responsible for the increased permeability. In agreement with our data, recent studies have shown that pro-inflammatory conditions increase the opening of Panxl channels in microglia (Orellana et al., 2013; Sáez et al., 2013). Both astrocytes and neurons exhibited similar increases on Etd uptake after prenatal nicotine and postnatal HFC diet. However, this effect was due to $\mathrm{Cx} 43 \mathrm{HCs}$ in the former, as mimetic peptides known to block these channels (Wang et al., 2013a), completely inhibited astroglial cell Etd uptake. In contrast, ${ }^{10}$ panxl and probenecid did not affect astroglial cell Etd uptake. On the other hand, neuronal Etd uptake induced by prenatal nicotine and postnatal HFC diet was drastically blocked by ${ }^{10}$ panx1 and probenecid but not by TAT-L2, Gap19 or Gap26, indicating that Panx1 channels were the main contributors for this response.

Glutamate and ATP are considered key mediators on neuronglia crosstalk. Thereby, their release through membrane proteins and vesicles is tightly regulated (Fields and Burnstock, 2006; Perea and Araque, 2010). In fact, high concentrations of glutamate and ATP at the synaptic cleft under pathological conditions could result in neurotoxicity (Lau and Tymianski, 2010; Arbeloa et al., 2012; Ashpole et al., 2013). As mentioned before, part of neuronal damage could depend on the release of glutamate and ATP via HCs and PCHs (Takeuchi et al., 2006; Garré et al., 2010; Orellana et al., 2011a,b). Both glutamate and ATP released by glial cells trigger the activation of neuronal NMDA and P2X7 receptors, which result in the opening of neuronal Panx1 channels and further cell death (Orellana et al., 2011a,b). Our results indicate that release of glutamate and ATP evoked by prenatal nicotine and postnatal HFC diet occurred via Cx43 and Panx1 unopposed channels, as it was inhibited by TAT-L2, Gap19, Gap26, ${ }^{10}$ panx1 and probenecid. Nevertheless, given that neuronal Etd uptake still 


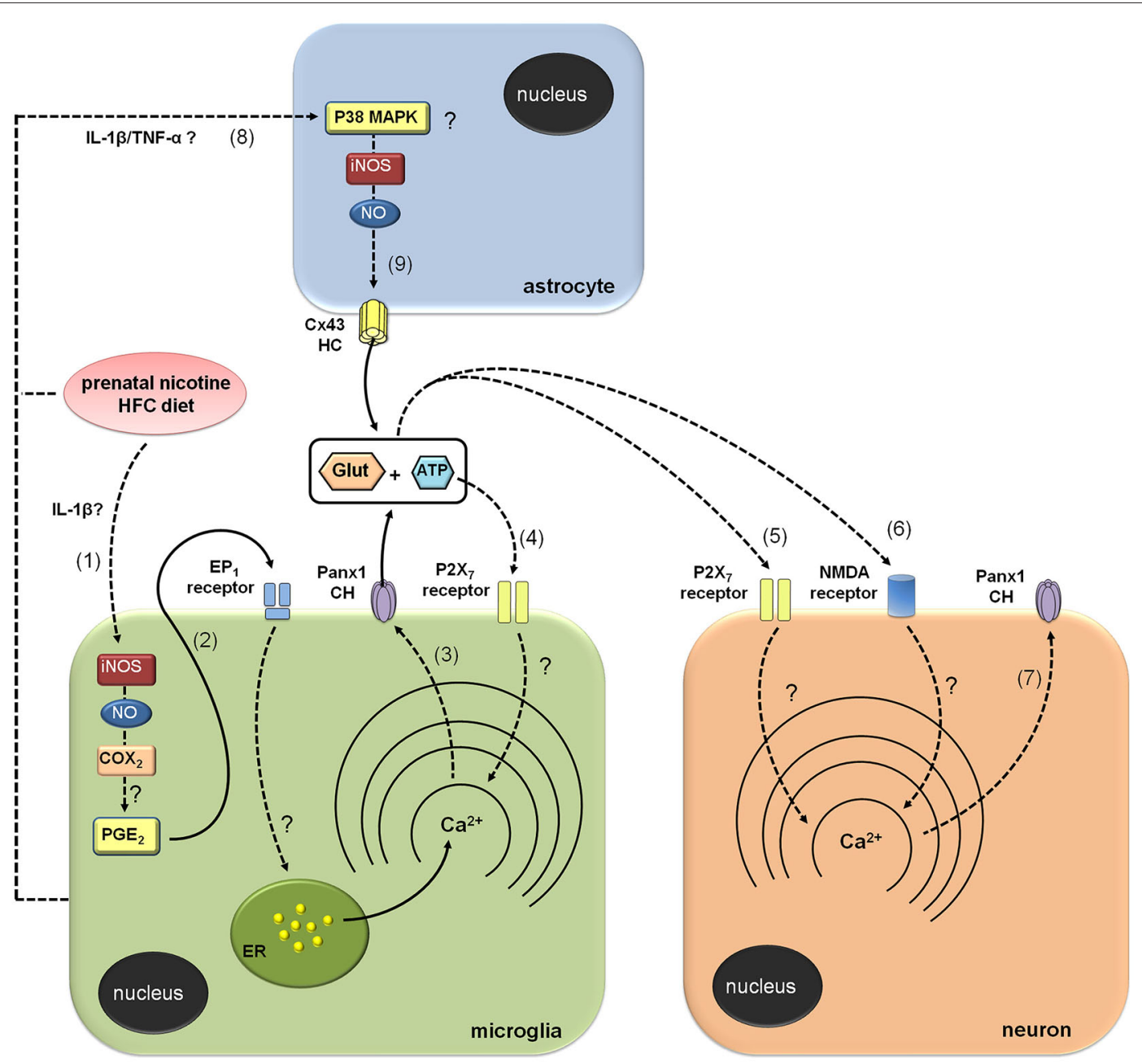

FIGURE 7 | Modulation of brain cell hemichannels by prenatal nicotine and postnatal high-fat/cholesterol diet. Prenatal nicotine and postnatal high-fat/cholesterol diet increase serum levels of IL-1 $\beta$, leading to iNOS/COX 2 activation in microglia (1) and likely in astrocytes and neurons (not depicted). Possibly, $\mathrm{PGE}_{2}$ released from microglia binds its $E P_{1}$ metabotropic receptors and produces the release of $\mathrm{Ca}^{2+}$ from intracellular stores (2). The increases in $\left[\mathrm{Ca}^{2+}\right]_{i}$ is a known condition that evokes opening of Panx 1 channels (Panx1 CHs), allowing the release of glutamate and ATP through them (3). ATP released via Panx $1 \mathrm{CHs}$ activates $\mathrm{P} 2 \mathrm{X}_{7}$ receptors (4), triggering a self-perpetuating mechanism, in which high levels of $\left[\mathrm{Ca}^{2+}\right]_{i}$ could reactivate Panx1 CHs in microglia. In addition, paracrine release of glutamate and ATP from microglia could act on neighboring or distant neurons, resulting in the activation of $\mathrm{P}^{2} \mathrm{X}_{7}$ (5) and NMDA (6) receptors, respectively. The latter enhances the activity of neuronal Panx1 CHs (7), allowing more release of ATP/glutamate and altering physiological functions of neurons (not depicted). Prenatal nicotine and postnatal high-fat/cholesterol diet could increase the release of glutamate and ATP from astrocytes via opening of $\mathrm{C} \times 43$ hemichannels ( $\mathrm{C} \times 43 \mathrm{HCs} ; 9)$. It is possible that microglia through the release of pro-inflammatory molecules (e.g., IL-1 $\beta$ and TNF- $\alpha$ ) could contribute to the opening of astroglial $\mathrm{C} \times 43 \mathrm{HCs}$ via the activation of a p38MAPK/iNOS-dependent pathway. persist under Cx43 but not Panx1 channel blockade, it seems that glutamate and ATP released from microglia rather than astrocytes are the major contributors to the opening of Panxl unopposed channels in neurons (Figure 7).

How does the exposure to prenatal nicotine and postnatal HFC diet induce the opening of $\mathrm{Cx} 43$ and Panx1 unopposed channels? Previous studies have demonstrated that opening of these channels in microglia and astrocytes results on the activation of an iNOS/COX $2 / \mathrm{EP}_{1}$ receptor- and $\mathrm{p} 38 \mathrm{MAPK} / \mathrm{iNOS}$ dependent pathway, respectively (Retamal et al., 2007; Orellana et al., 2013). In agreement with that mechanism, Etd uptake and gliotransmitter release were nearly abolished by blockers of iNOS, $\mathrm{COX}_{2}$ and $\mathrm{EP}_{1}$ receptor, suggesting that activation of $\mathrm{Cx} 43$ and Panx1 unopposed channels likely occurred downstream of this pathway. Given that activation of $\mathrm{EP}_{1}$ receptors raises $\left[\mathrm{Ca}^{2+}\right]_{i}$ (Woodward et al., 2011), opening of these channels possibly occurred by this mechanism, which is coherent with previous studies showing that increased levels of $\left[\mathrm{Ca}^{2+}\right]_{i}$ are necessary for gliotransmitter release via $\mathrm{HCs}$ and $\mathrm{PCH}$ (Locovei et al., 2006; Torres et al., 2012). This is also in agreement with the fact that $\mathrm{P} 2 \mathrm{X}_{7}$ receptor activation, a well known mechanism that increases $\left[\mathrm{Ca}^{2+}\right]_{i}$, was required to induce the release of glutamate and ATP we observed. By contrast, blockade of NMDA receptors, whose activation also enhances $\left[\mathrm{Ca}^{2+}\right]_{i}$ levels, 
did not induce the same response. These data support the idea that ATP, but not glutamate, evokes its own release via Panx1 unopposed channels, and subsequent activation of purinergic receptors in microglia, as has been previously observed (Orellana et al., 2013; Figure 7). Previous studies have described that astrocytes exposed to activated microglia exhibit an increased Cx43 hemichannel opening sensitive to L-NAME (a broad range NOS inhibitor) and p38 MAPK inhibitors (Retamal et al., 2007). Therefore, it is conceivable to speculate that along with direct effect of nicotine and HFC diet on astrocytes, microglia might also contribute to the opening of astroglial HCs by releasing proinflammatory cytokines (see below; Figure 7). Whether specific crosstalk (e.g., through $\mathrm{P}_{2} \mathrm{X}_{7}$ receptors, $\mathrm{HCs}$ and $\mathrm{PCHs}$ ) between astrocytes and microglia could explain their different contribution to neuronal Panxl channel opening will be a matter of future investigation.

It has been described that nicotine exposure increases peripheral and brain levels of inflammatory cytokines, including IL-1 $\beta$ (Lau et al., 2006; Bradford et al., 2011). We speculate that prenatal nicotine exposure could affect the inflammatory state of dams, resulting in epigenetic modification of brain genes, leading to permanent changes in gene expression and long-term changes in structure and function (Boksa, 2010). Here, we found that the brain of adult offspring from nicotine-treated dams are sensitized to postnatal HFC diet, as has been previously described to occur with others environmental challenges (Slotkin et al., 1991; Bilbo et al., 2005). Given that feeding mice a cholesterol-enriched diet during adulthood results in a general inflammatory state (Thirumangalakudi et al., 2008; Lewis et al., 2010), this condition could act as a second inflammatory challenge affecting the CNS. Accordingly, we found that prenatal nicotine and postnatal cholesterolenriched diet induced higher serum levels of IL- $1 \beta$ compared to control conditions.

Elevated blood levels of cytokines correlate with increased brain levels of cytokines (Erickson and Banks, 2011), being the latter closely linked to activation of iNOS, $\mathrm{COX}_{2}$ and $\mathrm{EP}_{1}$ receptors (Vinukonda et al., 2010; Sheng et al., 2011; Samy and Igwe, 2012). Therefore, it is plausible to speculate that increased brain levels of IL- $1 \beta$ and activation of $\mathrm{iNOS} / \mathrm{COX}_{2} / \mathrm{EP}_{1}$ receptor pathway could be involved in the increased opening of $\mathrm{Cx} 43$ and Panx 1 unopposed channels observed in our model (Figure 7). Supporting this idea, IL-1 $\beta$ causes opening of HCs and changes connexin expression in brain cells (Retamal et al., 2007; Froger et al., 2009, 2010; Orellana et al., 2011a; Xiong et al., 2012). Here, we observed that prenatal nicotine and postnatal HFC diet reduced $\mathrm{Cx} 43$ expression in astrocytes. Given that surface HCs account for $\sim 11 \%$ of total $\mathrm{Cx} 43$ under resting conditions (Schalper et al., 2008), making them less detectable by immunofluorescence than gap junctions plaques, a reduction on $\mathrm{Cx} 43$ immunodetection not necessarily implicates a decrease on surface HCs or in their activity. On the other hand, Panx1 expression was increased in pyramidal neurons. It is possible that part of Etd uptake observed in pyramidal neurons could rely on this phenomenon. Further studies are required to elucidate whether changes in protein expression could contribute as well to the $\mathrm{Cx} 43$ and Panx1 unopposed channel activity triggered by prenatal nicotine and postnatal HFC diet.
Diverse studies have shown that cell and tissue responses to injuries depend on properties of the cells (e.g., age, hormonal exposure, and stage of cell cycle) and insult (e.g., duration, intensity, and quality). Moreover, CNS responses depend on interactions between their constituent cells, including chemical and electrical transmission as well as paracrine and autocrine signaling (e.g., by cytokines and ROS), possibly mediated by HCs and PCHs. In most chronic diseases, additional mechanisms are progressively added to the primary cause and thus, complicating the assignment of contribution of each factor to the final condition. Under this view, we speculate that the combined effect of two stressors (exposure to prenatal nicotine and postnatal HFC diet) resulted in our system in an synergic outcome on the increased activity of HCs and PCHs in brain cells, as has been previously observed in other inflammatory models (Orellana et al., 2010). Despite the difficulty of assigning contributions to connexin and pannexin unopposed channels in the pathogenesis of neurodegenerative diseases, recent studies using homo and/or heterocellular cultures have provided clues to elucidate this matter (Sáez and Leybaert, 2014). Although our model does not recapitulate completely mechanisms underlying brain abnormalities induced by maternal cigarette smoking, it allows us to dissect the specific contribution of HCs and PCHs expressed by individual brain cell types. Our findings bring new light on how gliotransmitters and the unbalance on paracrine signaling mediated by HCs and PCHs could contribute to developing brain abnormalities induced by different stressors during pregnancy.

\section{ACKNOWLEDGMENTS}

This work was partially supported by CONICYT collaborative grant 79090028 to Juan A. Orellana and Dolores Busso and FONDECYT grants 11121133 to Juan A. Orellana, 11090064 and 1141236 to Dolores Busso, 1110712 to Attilio Rigotti, 1130874 to Jaime Eugenín, 1131025 to Rommy von Bernhardi.

\section{REFERENCES}

Amitai, Y. (2010). Physiologic role for "inducible" nitric oxide synthase: a new form of astrocytic-neuronal interface. Glia 58, 1775-1781. doi: 10.1002/glia. 21057

Arbeloa, J., Pérez-Samartin, A., Gottlieb, M., and Matute, C. (2012). P2X7 receptor blockade prevents ATP excitotoxicity in neurons and reduces brain damage after ischemia. Neurobiol. Dis. 45, 954-961. doi: 10.1016/j.nbd.2011.12. 014

Ashpole, N. M., Chawla, A. R., Martin, M. P., Brustovetsky, T., Brustovetsky, N., and Hudmon, A. (2013). Loss of calcium/calmodulin-dependent protein kinase II activity in cortical astrocytes decreases glutamate uptake and induces neurotoxic release of ATP. J. Biol. Chem. 288, 14599-14611. doi: 10.1074/jbc.M113. 466235

Bilbo, S. D., Levkoff, L. H., Mahoney, J. H., Watkins, L. R., Rudy, J. W., and Maier, S. F. (2005). Neonatal infection induces memory impairments following an immune challenge in adulthood. Behav. Neurosci. 119, 293-301. doi: 10. 1037/0735-7044.119.1.293

Block, M. L., Zecca, L., and Hong, J. S. (2007). Microglia-mediated neurotoxicity: uncovering the molecular mechanisms. Nat. Rev. Neurosci. 8, 57-69. doi: 10. $1038 /$ nrn 2038

Boksa, P. (2010). Effects of prenatal infection on brain development and behavior: a review of findings from animal models. Brain Behav. Immun. 24, 881-897. doi: 10.1016/j.bbi.2010.03.005

Bradford, S. T., Stamatovic, S. M., Dondeti, R. S., Keep, R. F., and Andjelkovic, A. V. (2011). Nicotine aggravates the brain postischemic inflammatory response. Am. 
J. Physiol. Heart Circ. Physiol. 300, H1518-H1529. doi: 10.1152/ajpheart.00928. 2010

Burkovetskaya, M., Karpuk, N., Xiong, J., Bosch, M., Boska, M. D., Takeuchi, H., et al. (2014). Evidence for Aberrant Astrocyte Hemichannel activity in Juvenile Neuronal Ceroid Lipofuscinosis (JNCL). PLoS One 9:e95023. doi: 10. 1371/journal.pone.0095023

Coddou, C., Bravo, E., and Eugenín, J. (2009). Alterations in cholinergic sensitivity of respiratory neurons induced by pre-natal nicotine: a mechanism for respiratory dysfunction in neonatal mice. Philos. Trans. R. Soc. Lond. B Biol. Sci. 364, 2527-2535. doi: 10.1098/rstb.2009.0078

Contreras, J. E., Sánchez, H. A., Eugenin, E. A., Speidel, D., Theis, M., Willecke, K., et al. (2002). Metabolic inhibition induces opening of unapposed connexin 43 gap junction hemichannels and reduces gap junctional communication in cortical astrocytes in culture. Proc. Natl. Acad. Sci. U S A 99, 495-500. doi: 10. 1073/pnas.012589799

DiFranza, J. R., and Lew, R. A. (1995). Effect of maternal cigarette smoking on pregnancy complications and sudden infant death syndrome. J. Fam. Pract. 40, 385-394.

Dufour, F., Liu, Q. Y., Gusev, P., Alkon, D., and Atzori, M. (2006). Cholesterolenriched diet affects spatial learning and synaptic function in hippocampal synapses. Brain Res. 1103, 88-98. doi: 10.1016/j.brainres.2006.05.086

Dwyer, J. B., Broide, R. S., and Leslie, F. M. (2008). Nicotine and brain development. Birth Defects Res. C Embryo Today 84, 30-44. doi: 10.1002/bdrc.20118

Erickson, M. A., and Banks, W. A. (2011). Cytokine and chemokine responses in serum and brain after single and repeated injections of lipopolysaccharide: multiplex quantification with path analysis. Brain Behav. Immun. 25, 16371648. doi: 10.1016/j.bbi.2011.06.006

Eugenín, J., Otárola, M., Bravo, E., Coddou, C., Cerpa, V., Reyes-Parada, M., et al. (2008). Prenatal to early postnatal nicotine exposure impairs central chemoreception and modifies breathing pattern in mouse neonates: a probable link to sudden infant death syndrome. J. Neurosci. 28, 13907-13917. doi: 10. 1523/JNEUROSCI.4441-08.2008

Fields, R. D., and Burnstock, G. (2006). Purinergic signalling in neuron-glia interactions. Nat. Rev. Neurosci. 7, 423-436. doi: 10.1038/nrn1928

Froger, N., Orellana, J. A., Calvo, C. F., Amigou, E., Kozoriz, M. G., Naus, C. C., et al. (2010). Inhibition of cytokine-induced connexin 43 hemichannel activity in astrocytes is neuroprotective. Mol. Cell. Neurosci. 45, 37-46. doi: 10.1016/j. mcn.2010.05.007

Froger, N., Orellana, J. A., Cohen-Salmon, M., Ezan, P., Amigou, E., Sáez, J. C., et al. (2009). Cannabinoids prevent the opposite regulation of astroglial connexin 43 hemichannels and gap junction channels induced by pro-inflammatory treatments. J. Neurochem. 111, 1383-1397. doi: 10.1111/j.1471-4159.2009.06407.x

Garré, J. M., Retamal, M. A., Cassina, P., Barbeito, L., Bukauskas, F. F., Saez, J. C., et al. (2010). FGF-1 induces ATP release from spinal astrocytes in culture and opens pannexin and connexin hemichannels. Proc. Natl. Acad. Sci. U S A 107, 22659-22664. doi: 10.1073/pnas.1013793107

Gulbransen, B. D., Bashashati, M., Hirota, S. A., Gui, X., Roberts, J. A., Macdonald, J. A., et al. (2012). Activation of neuronal P2X7 receptor-pannexin-1 mediates death of enteric neurons during colitis. Nat. Med. 18, 600-604. doi: 10.1038/nm. 2679

Huckstepp, R. T. R., id Bihi, R., Eason, R., Spyer, K. M., Dicke, N., Willecke, K., et al. (2010). Connexin hemichannel-mediated CO2-dependent release of ATP in the medulla oblongata contributes to central respiratory chemosensitivity. $J$. Physiol. 588, 3901-3920. doi: 10.1113/jphysiol.2010.192088

Iglesias, R., Dahl, G., Qiu, F., Spray, D. C., and Scemes, E. (2009). Pannexin 1: the molecular substrate of astrocyte "hemichannels". J. Neurosci. 29, 7092-7097. doi: 10.1523/JNEUROSCI.6062-08.2009

Jacobsen, L. K., Slotkin, T. A., Westerveld, M., Mencl, W. E., and Pugh, K. R. (2006). Visuospatial memory deficits emerging during nicotine withdrawal in adolescents with prenatal exposure to active maternal smoking. Neuropsychopharmacology 31, 1550-1561. doi: 10.1038/sj.npp.1300981

Julvez, J., Ribas-Fitó, N., Torrent, M., Forns, M., Garcia-Esteban, R., and Sunyer, J. (2007). Maternal smoking habits and cognitive development of children at age 4 years in a population-based birth cohort. Int. J. Epidemiol. 36, 825-832. doi: 10. 1093/ije/dym 107

Karpuk, N., Burkovetskaya, M., Fritz, T., Angle, A., and Kielian, T. (2011). Neuroinflammation leads to region-dependent alterations in astrocyte gap junction communication and hemichannel activity. J. Neurosci. 31, 414-425. doi: 10. 1523/JNEUROSCI.5247-10.2011
Lau, P. P., Li, L., Merched, A. J., Zhang, A. L., Ko, K. W., and Chan, L. (2006). Nicotine induces proinflammatory responses in macrophages and the aorta leading to acceleration of atherosclerosis in low-density lipoprotein receptor(-/-) mice. Arterioscler. Thromb. Vasc. Biol. 26, 143-149. doi: 10.1161/01.ATV.0000193510. 19000.10

Lau, A., and Tymianski, M. (2010). Glutamate receptors, neurotoxicity and neurodegeneration. Pflugers Arch. 460, 525-542. doi: 10.1007/s00424-010-0809-1

Lewis, D. K., Bake, S., Thomas, K., Jezierski, M. K., and Sohrabji, F. (2010). A high cholesterol diet elevates hippocampal cytokine expression in an age and estrogen-dependent manner in female rats. J. Neuroimmunol. 223, 31-38. doi: 10.1016/j.jneuroim.2010.03.024

Lin, J. H., Lou, N., Kang, N., Takano, T., Hu, F., Han, X., et al. (2008). A central role of connexin 43 in hypoxic preconditioning. J. Neurosci. 28, 681-695. doi: 10. 1523/JNEUROSCI.3827-07.2008

Locovei, S., Wang, J., and Dahl, G. (2006). Activation of pannexin 1 channels by ATP through P2Y receptors and by cytoplasmic calcium. FEBS Lett. 580, 239244. doi: 10.1016/j.febslet.2005.12.004

Luck, W., Nau, H., Hansen, R., and Steldinger, R. (1985). Extent of nicotine and cotinine transfer to the human fetus, placenta and amniotic fluid of smoking mothers. Dev. Pharmacol. Ther. 8, 384-395.

Morton, D. B., and Griffiths, P. H. (1985). Guidelines on the recognition of pain, distress and discomfort in experimental animals and an hypothesis for assessment. Vet. Rec. 116, 431-436. doi: 10.1136/vr.116.16.431

Muneoka, K., Ogawa, T., Kamei, K., Muraoka, S., Tomiyoshi, R., Mimura, Y., et al. (1997). Prenatal nicotine exposure affects the development of the central serotonergic system as well as the dopaminergic system in rat offspring: involvement of route of drug administrations. Brain Res. Dev. Brain Res. 102, 117-126. doi: 10.1016/S0165-3806(97)00092-8

Naeye, R. L., and Peters, E. C. (1984). Mental development of children whose mothers smoked during pregnancy. Obstet. Gynecol. 64, 601-607.

Navarro, H. A., Seidler, F. J., Schwartz, R. D., Baker, F. E., Dobbins, S. S., and Slotkin, T. A. (1989). Prenatal exposure to nicotine impairs nervous system development at a dose which does not affect viability or growth. Brain Res. Bull. 23, 187-192. doi: 10.1016/0361-9230(89)90146-9

Orellana, J. A., Froger, N., Ezan, P., Jiang, J. X., Bennett, M. V., Naus, C. C., et al. (2011a). ATP and glutamate released via astroglial connexin 43 hemichannels mediate neuronal death through activation of pannexin 1 hemichannels. J. Neurochem. 118, 826-840. doi: 10.1111/j.1471-4159.2011.07210.x

Orellana, J. A., Hernández, D. E., Ezan, P., Velarde, V., Bennett, M. V., Giaume, C., et al. (2010). Hypoxia in high glucose followed by reoxygenation in normal glucose reduces the viability of cortical astrocytes through increased permeability of connexin 43 hemichannels. Glia 58, 329-343. doi: 10.1002/glia.20926

Orellana, J. A., Montero, T. D., and von Bernhardi, R. (2013). Astrocytes inhibit nitric oxide-dependent $\mathrm{Ca}(2+)$ dynamics in activated microglia: involvement of ATP released via pannexin 1 channels. Glia 61, 2023-2037. doi: 10.1002/glia. 22573

Orellana, J. A., Sáez, P. J., Cortés-Campos, C., Elizondo, R. J., Shoji, K. F., ContrerasDuarte, S., et al. (2012). Glucose increases intracellular free $\mathrm{Ca}(2+)$ in tanycytes via ATP released through connexin 43 hemichannels. Glia 60, 53-68. doi: 10. 1002/glia.21246

Orellana, J. A., Sáez, P. J., Shoji, K. F., Schalper, K. A., Palacios-Prado, N., Velarde, V., et al. (2009). Modulation of brain hemichannels and gap junction channels by pro-inflammatory agents and their possible role in neurodegeneration. Antioxid. Redox Signal. 11, 369-399. doi: 10.1089/ars.2008.2130

Orellana, J. A., Shoji, K. F., Abudara, V., Ezan, P., Amigou, E., Sáez, P. J., et al. (2011b). Amyloid $\beta$-induced death in neurons involves glial and neuronal hemichannels. J. Neurosci. 31, 4962-4977. doi: 10.1523/JNEUROSCI.6417-10. 2011

Pelegrin, P., and Surprenant, A. (2006). Pannexin-1 mediates large pore formation and interleukin-1beta release by the ATP-gated P2X7 receptor. EMBO J. 25, 5071-5082. doi: 10.1038/sj.emboj.7601378

Perea, G., and Araque, A. (2010). Glia modulates synaptic transmission. Brain Res. Rev. 63, 93-102. doi: 10.1016/j.brainresrev.2009.10.005

Perea, G., Navarrete, M., and Araque, A. (2009). Tripartite synapses: astrocytes process and control synaptic information. Trends Neurosci. 32, 421-431. doi: 10. 1016/j.tins.2009.05.001

Rantakallio, P., and Koiranen, M. (1987). Neurological handicaps among children whose mothers smoked during pregnancy. Prev. Med. 16, 597-606. doi: 10. 1016/0091-7435(87)90043-0 
Retamal, M. A., Froger, N., Palacios-Prado, N., Ezan, P., Sáez, P. J., Sáez, J. C., et al. (2007). Cx43 hemichannels and gap junction channels in astrocytes are regulated oppositely by proinflammatory cytokines released from activated microglia. J. Neurosci. 27, 13781-13792. doi: 10.1523/JNEUROSCI.2042-07. 2007

Rouach, N., Avignone, E., Même, W., Koulakoff, A., Venance, L., Blomstrand, F., et al. (2002). Gap junctions and connexin expression in the normal and pathological central nervous system. Biol. Cell 94, 457-475. doi: 10.1016/S02484900(02)00016-3

Roy, T. S., and Sabherwal, U. (1994). Effects of prenatal nicotine exposure on the morphogenesis of somatosensory cortex. Neurotoxicol. Teratol. 16, 411-421. doi: 10.1016/0892-0362(94)90030-2

Roy, T. S., and Sabherwal, U. (1998). Effects of gestational nicotine exposure on hippocampal morphology. Neurotoxicol. Teratol. 20, 465-473. doi: 10.1016/S08920362(97)00137-2

Roy, T. S., Seidler, F. J., and Slotkin, T. A. (2002). Prenatal nicotine exposure evokes alterations of cell structure in hippocampus and somatosensory cortex. J. Pharmacol. Exp. Ther. 300, 124-133. doi: 10.1124/jpet.300.1.124

Sáez, J. C., and Leybaert, L. (2014). Hunting for connexin hemichannels. FEBS Lett. 588, 1205-1211. doi: 10.1016/j.febslet.2014.03.004

Sáez, P. J., Shoji, K. F., Retamal, M. A., Harcha, P. A., Ramirez, G., Jiang, J. X., et al. (2013). ATP is required and advances cytokine-induced gap junction formation in microglia in vitro. Mediators Inflamm. 2013:216402. doi: 10. $1155 / 2013 / 216402$

Salvemini, D., Misko, T. P., Masferrer, J. L., Seibert, K., Currie, M. G., and Needleman, P. (1993). Nitric oxide activates cyclooxygenase enzymes. Proc. Natl. Acad. Sci. U S A 90, 7240-7244. doi: 10.1073/pnas.90.15.7240

Samy, A. S., and Igwe, O. J. (2012). Regulation of IL-1beta-induced cyclooxygenase2 expression by interactions of Abeta peptide, apolipoprotein $\mathrm{E}$ and nitric oxide in human neuroglioma. J. Mol. Neurosci. 47, 533-545. doi: 10.1007/s12031-0119670-8

Schalper, K. A., Palacios-Prado, N., Orellana, J. A., and Sáez, J. C. (2008). Currently used methods for identification and characterization of hemichannels. Cell Commun. Adhes. 15, 207-218. doi: 10.1080/15419060802014198

Schneider, T., Ilott, N., Brolese, G., Bizarro, L., Asherson, P. J., and Stolerman, I. P. (2011). Prenatal exposure to nicotine impairs performance of the 5-choice serial reaction time task in adult rats. Neuropsychopharmacology 36, 1114-1125. doi: $10.1038 /$ npp. 2010.249

Sheng, W., Zong, Y., Mohammad, A., Ajit, D., Cui, J., Han, D., et al. (2011). Pro-inflammatory cytokines and lipopolysaccharide induce changes in cell morphology and upregulation of ERK1/2, iNOS and sPLA(2)-IIA expression in astrocytes and microglia. J. Neuroinflammation 8:121. doi: 10.1186/1742-20948-121

Shestopalov, V. I., and Slepak, V. Z. (2014). Molecular pathways of pannexin1mediated neurotoxicity. Front. Physiol. 5:23. doi: 10.3389/fphys.2014. 00023

Silverman, W., Locovei, S., and Dahl, G. (2008). Probenecid, a gout remedy, inhibits pannexin 1 channels. Am. J. Physiol. Cell Physiol. 295, C761-C767. doi: 10. 1152/ajpcell.00227.2008

Slotkin, T. A., Lappi, S. E., Tayyeb, M. I., and Seidler, F. J. (1991). Chronic prenatal nicotine exposure sensitizes rat brain to acute postnatal nicotine challenge as assessed with ornithine decarboxylase. Life Sci. 49, 665-670. doi: 10.1016/00243205(91)90113-P

Stehberg, J., Moraga-Amaro, R., Salazar, C., Becerra, A., Echeverria, C., Orellana, J. A., et al. (2012). Release of gliotransmitters through astroglial connexin 43 hemichannels is necessary for fear memory consolidation in the basolateral amygdala. FASEB J. 26, 3649-3657. doi: 10.1096/fj.11-198416

Takeuchi, H., Jin, S., Wang, J., Zhang, G., Kawanokuchi, J., Kuno, R., et al. (2006). Tumor necrosis factor-alpha induces neurotoxicity via glutamate release from hemichannels of activated microglia in an autocrine manner. J. Biol. Chem. 281, 21362-21368. doi: 10.1074/jbc.M600504200

Thirumangalakudi, L., Prakasam, A., Zhang, R., Bimonte-Nelson, H., Sambamurti, K., Kindy, M. S., et al. (2008). High cholesterol-induced neuroinflammation and amyloid precursor protein processing correlate with loss of working memory in mice. J. Neurochem. 106, 475-485. doi: 10.1111/j.1471-4159.2008. 05415.x
Thompson, R. J., Jackson, M. F., Olah, M. E., Rungta, R. L., Hines, D. J., Beazely, M. A., et al. (2008). Activation of pannexin-1 hemichannels augments aberrant bursting in the hippocampus. Science 322, 1555-1559. doi: 10.1126/science. 1165209

Thompson, R. J. R., Zhou, N. N., and Macvicar, B. A. (2006). Ischemia opens neuronal gap junction hemichannels. Science 312, 924-927. doi: 10.1126/science. 1126241

Toledo-Rodriguez, M., Lotfipour, S., Leonard, G., Perron, M., Richer, L., Veillette, S., et al. (2010). Maternal smoking during pregnancy is associated with epigenetic modifications of the brain-derived neurotrophic factor- 6 exon in adolescent offspring. Am. J. Med. Genet. B Neuropsychiatr. Genet. 153B, 1350-1354. doi: 10.1002/ajmg.b.31109

Torres, A., Wang, F., Xu, Q., Fujita, T., Dobrowolski, R., Willecke, K., et al. (2012). Extracellular $\mathrm{Ca}(2)(+)$ acts as a mediator of communication from neurons to glia. Sci. Signal. 5:ra8. doi: 10.1126/scisignal.2002160

Triviño, A., Ramírez, A. I., Salazar, J. J., De Hoz, R., Rojas, B., Padilla, E., et al. (2006). A cholesterol-enriched diet induces ultrastructural changes in retinal and macroglial rabbit cells. Exp. Eye Res. 83, 357-366. doi: 10.1016/j.exer.2005. 12.020

Tzeng, S. F., Hsiao, H. Y., and Mak, O. T. (2005). Prostaglandins and cyclooxygenases in glial cells during brain inflammation. Curr. Drug Targets Inflamm. Allergy 4, 335-340. doi: 10.2174/1568010054022051

van de Kamp, J. L., and Collins, A. C. (1994). Prenatal nicotine alters nicotinic receptor development in the mouse brain. Pharmacol. Biochem. Behav. 47, 889900. doi: 10.1016/0091-3057(94)90293-3

Vinukonda, G., Csiszar, A., Hu, F., Dummula, K., Pandey, N. K., Zia, M. T., et al. (2010). Neuroprotection in a rabbit model of intraventricular haemorrhage by cyclooxygenase-2, prostanoid receptor-1 or tumour necrosis factor-alpha inhibition. Brain 133, 2264-2280. doi: 10.1093/brain/awq107

Wang, N., De Bock, M., Decrock, E., Bol, M., Gadicherla, A., Bultynck, G., et al. (2013a). Connexin targeting peptides as inhibitors of voltage- and intracellular Ca2+-triggered Cx43 hemichannel opening. Neuropharmacology 75, 506-516. doi: 10.1016/j.neuropharm.2013.08.021

Wang, N., De Bock, M., Decrock, E., Bol, M., Gadicherla, A., Vinken, M., et al. (2013b). Paracrine signaling through plasma membrane hemichannels. Biochim. Biophys. Acta 1828, 35-50. doi: 10.1016/j.bbamem.2012.07.002

Woodward, D. F., Jones, R. L., and Narumiya, S. (2011). International Union of Basic and Clinical Pharmacology. LXXXIII: classification of prostanoid receptors, updating 15 years of progress. Pharmacol. Rev. 63, 471-538. doi: 10.1124/pr. 110.003517

Xiong, J., Burkovetskaya, M., Karpuk, N., and Kielian, T. (2012). IL-1RI (interleukin-1 receptor type I) signalling is essential for host defence and hemichannel activity during acute central nervous system bacterial infection. ASN Neuro 4:e00085. doi: 10.1042/AN20120008

Ya, B. L., Liu, W. Y., Ge, F., Zhang, Y. X., Zhu, B. L., and Bai, B. (2013). Dietary cholesterol alters memory and synaptic structural plasticity in young rat brain. Neurol. Sci. 34, 1355-1365. doi: 10.1007/s10072-012-1241-4

Conflict of Interest Statement: The authors declare that the research was conducted in the absence of any commercial or financial relationships that could be construed as a potential conflict of interest.

Received: 22 July 2014; accepted: 08 November 2014; published online: 02 December 2014.

Citation: Orellana JA, Busso D, Ramírez G, Campos M, Rigotti A, Eugenín J and von Bernhardi R (2014) Prenatal nicotine exposure enhances CX43 and Panxl unopposed channel activity in brain cells of adult offspring mice fed a high-fat/cholesterol diet. Front. Cell. Neurosci. 8:403. doi: 10.3389/fncel.2014.00403

This article was submitted to the journal Frontiers in Cellular Neuroscience.

Copyright (C) 2014 Orellana, Busso, Ramírez, Campos, Rigotti, Eugenin and von Bernhardi. This is an open-access article distributed under the terms of the Creative Commons Attribution License (CC BY). The use, distribution and reproduction in other forums is permitted, provided the original author(s) or licensor are credited and that the original publication in this journal is cited, in accordance with accepted academic practice. No use, distribution or reproduction is permitted which does not comply with these terms. 